\title{
POPLITEAL ARTERY INJURY DURING ANTERIOR CRUCIATE LIGAMENT RECONSTRUCTION: BRIEF REPORT
}

\author{
J. H. ROTH, R. C. BRAY
}

Complications of intra-articular reconstruction of the anterior cruciate ligament usually involve arthrofibrosis, recurrent instability and patellofemoral derangement (Hughston 1985). We report a case of intra-operative injury to the popliteal artery.

Case report. A 29-year-old man with chronic instability of the knee due to a volleyball injury had an anterior cruciate ligament reconstruction using a polypropylene ligament augmentation device and the middle third of the quadriceps-patellar tendon (Roth et al. 1985). A wire-passing device was used to place the composite graft, which was securely fixed "over-the-top" to the lateral femur with a single staple.

Four to six hours after operation, the patient complained of burning pain in the sole of the foot. There was no evidence of haematoma in the popliteal space, but the pedal pulses were difficult to palpate. A Doppler examination demonstrated arterial signals in the posterior tibial and dorsalis pedis arteries. There was no clinical evidence of compartment ischaemia.

A diagnosis of arterial spasm secondary to dissection of the popliteal structures was made. The pain and dysaesthesia settled, but three weeks later the patient developed dull aching in the posterior calf and after six weeks the pain and dysaesthesia in the foot recurred; this was related to activity. An arteriogram showed an abrupt occlusion of the popliteal artery $7 \mathrm{~cm}$ above the joint line (Fig. 1).

The popliteal fossa was explored. The artery was pulsatile proximally, but at the margin of the joint capsule it was tightly trapped between the composite graft and bone. A saphenous vein graft was inserted, bypassing the entrapped portion of the artery. Postoperatively the patient's pain improved and muscle function returned to normal, but hyperaesthesia continued in the distal leg and sole. The knee has remained stable with a negative pivot-shift and Grade II laxity on Lachman's test.

Discussion. Collateral vessels about the knee provide an unpredictable contribution to limb perfusion (DeBakey and Simeone 1946). Trauma to these collateral vessels

\footnotetext{
J. H. Roth, MD, FRCS(C), Clinical Associate Professor

R. C. Bray, MD, FRCS(C), Clinical Lecturer

Division of Orthopaedic Surgery, University of Western Ontario, Victoria Hospital, London, Ontario, Canada.

Correspondence to Dr J. H. Roth, 345 Westminster Avenue, London, Ontario, Canada N6C 4V3.

(C) 1988 British Editorial Society of Bone and Joint Surgery $0301-620 X / 88 / 5 R 76 \$ 2.00$

J Bone Joint Surg [Br] 1988;70-B:840.
}

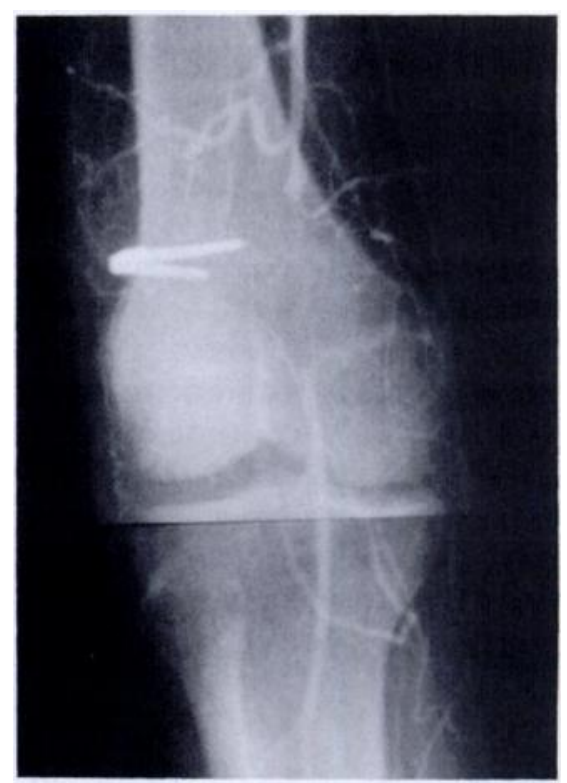

Fig. 1

further reduces limb perfusion after a blunt injury such as knee dislocation, (Snyder 1982), but the local occlusion of the popliteal artery in our case did not cause complete loss of perfusion. Collateral flow was undisturbed and sufficient to maintain limb viability.

In our patient, even with the use of a wire-passing device, the popliteal artery was entrapped. This device must be used with its tip directly apposed to bone and guided by a finger. We recommend that the tourniquet be released and distal pulsation of the popliteal artery confirmed after graft fixation.

Our case shows the value of arteriography over clinical and Doppler assessment of isolated injury to the popliteal artery, and warns against a potentially devastating complication of anterior cruciate ligament recon- struction or any intra-articular procedure which involves dissection of popliteal structures.

No benefits in any form have been received or will be received from a commercial party related directly or indirectly to the subject of this article.

\section{REFERENCES}

DeBakey ME, Simeone FA. Battle injuries of the arteries in World War II: an analysis of 2471 cases. Ann Surg 1946:123:534-79.

Hughston JC. Complications of anterior cruciate ligament surgery. Orthop Clin North Am 1985;16:237-40.

Roth JH, Kennedy JC, Lockstadt H, McCallum CL, Cunning LA. Polypropylene braid augmented and nonaugmented intraarticular anterior cruciate ligament reconstruction. Am J Sports Med $1985 ; 13 ; 321-36$.

Snyder WH III. Vascular injuries near the knee : an updated series and overview of the problem. Surgery 1982;91:502-6. 